\title{
AÇÕES SINDICAIS E DO GRANDE CAPITAL: ALCANCES E LIMITES À AÇÃO COLETIVA
}

\author{
Silvia Maria Pereira de Araújo \\ Doutor, UFPR \\ e-mail: saraujo@swi.com.br
}

RESUMO: A pesquisa toma por base a ação dos metalúrgicos com a inserção do Paraná no circuito mundial de montagem e exportação de veículos, que se deu mais intensamente a partir dos primeiros anos do novo milênio. A produção enxuta da cadeia automotiva, em termos de integração econômica, tecnologia e gestão flexível do trabalho e a forma negocial descentralizada por empresas e a diversidade de acordos nas questões do trabalho colocaram desafios à ação do sindicato em franca expansão. Afeita a atender as reivindicações dos trabalhadores, a ação coletiva passou a enfrentar a fragmentação do mercado de trabalho, as exigências do capital organizado em rede e a atuação conjugada dos trabalhadores e centrais sindicais em intercâmbio com a realidade de outras empresas, sindicatos e países.

PALAVRAS-CHAVE: Ação sindical. Metalúrgicos. Ação coletiva. Montadoras. Cadeia Automotiva. Paraná. 
As intensas transformações sociais que ocorreram nas últimas três décadas no chamado mundo do trabalho foram provocadas por uma avalanche de inovações na organização da produção e do trabalho. A adoção de tecnologias informacionais e equipamentos a partir da microeletrônica e da robótica nas indústrias de ponta e, também, as inovadoras formas de gestão da mão de obra, inspiradas no toyotismo, integram o quadro do que se convencionou chamar reestruturação produtiva, processo marcado pela lógica da flexibilidade, originário no setor industrial, com avanço heterogêneo para outros setores e atividades. Conhecer as mudanças em curso, cujos efeitos se expandem para diferentes âmbitos da sociedade, passa a ser uma imposição à análise sociológica, para a sobrevivência e inserção de grupos sociais emergentes na vida econômica, cada vez mais integrada.

A literatura pertinente desdobra-se em compreender a complexidade dos fenômenos, provando concepções renovadas de espaço e tempo numa era para além da modernidade, de esgotamento da racionalidade instrumental e de limites à acumulação capitalista, como foi marcado o século XX. Autores mais radicais remetem a uma crise estrutural do capital e à necessidade de reconhecer traços das determinações do desenvolvimento desigual entre os países avançados e aqueles sob a lógica capitalista dominante. Entre os eventos significativos para essa transição histórica, arrolam-se as experiências estratégicas de desenvolvimento com transferência de tecnologia e afirmação de políticas neoliberais em países da Ásia, da África e da América, o fenômeno do desemprego estrutural crescente, o declínio do Estado de Bem Estar Social nos países centrais, o endividamento gradativo e interdependente de todos os países e o movimento do capital de caráter cada vez mais financeiro e fluído em direção a países de capitalismo emergente, apostando em grandes investimentos diretos. A moderna indústria automobilística flexível e enxuta é um desses exemplos de transição.

Visualizar a reestruturação produtiva imposta à indústria automotiva tradicional para adaptar-se às novas exigências do capital, equivale a acompanhar o deslocamento das contradições que se acumulam na, hoje pouco significativa, clássica divisão das atividades em setores primário, secundário e terciário. O capital financeiro em auto-expansão e a reestruturação produtiva migraram para países como o Brasil, onde, por exemplo, provocaram o processo de desconcentração da indústria automobilística na última década. Tem-se a geração de um novo tipo de 
produtividade, capaz de conectar diversos setores, na competição que é própria da natureza capitalista das ações, mas a ser despertada em cada área e conjunto de atividades, ao estabelecer elos que ultrapassam a dimensão estritamente econômica e situam-se no plano político-social. Desse modo, as montadoras que aportaram em fins da década de 1990, no Paraná, como a Renault e a Audi-Volkswagen, aqui chegaram reestruturadas, com plantas maduras e layout apropriado para desenvolver a trilogia capitalista da alta produtividade, maior competitividade e lucratividade garantida.

A implantação da recente indústria automobilística desenha uma nova geografia do setor (NABUCO et al., 2002) no país, ao compor um aparato de fornecedores de primeira, segunda e terceira linhas, nacionais e estrangeiros, conforme o grau de aproximação valorativa do "núcleo duro" da produção, integrados por sistemas de logística, informatização e robotização que conformam o complexo da cadeia automotiva, cujos cortes comparativos relatam onde e como o valor é agregado ao produto final ${ }^{1}$. A produção de veículos automotores, especialmente automóveis e utilitários, no Paraná, perfaz o circuito com mínima concepção e design nacionais e utilização de mão-de-obra de baixo custo. Essas condições das novas montadoras e seus fornecedores, juntamente com as empresas já existentes no Paraná, como a New Holland, fabricante de veículos agrícolas e a Volvo, empresa sueca produtora de ônibus e caminhões, a qual se encontrava na Cidade Industrial de Curitiba (CIC) desde os anos 1970 e, recentemente, passou por uma reestruturação produtiva, colocaram nova dimensão de enfrentamento de problemas à organização dos trabalhadores dentro e fora das fábricas. A presença de um contingente de trabalhadores com perfil redefinido -

\footnotetext{
${ }^{1}$ Originalmente pensadas a partir do setor industrial, as cadeias produtivas são integradas pelo conjunto das atividades capazes de agregar valor desde a entrada de matérias-primas até a distribuição de produtos acabados em uma empresa (Porter, 1999, p.85). A designação cadeia de valores confirma o impulso agregador de valor no processo produtivo. A idéia de cadeia produtiva expandiu-se para a interconexão entre e intra os setores econômicos em moldes flexíveis, sobretudo na atualidade, quando vem se impondo como estratégia de inclusão econômico-social pela participação na produção de valor e redistribuição da renda, a partir de diferentes circuitos produtivos. Assim, têm peso decisivo na lógica vigente: a questão da agregação de valor ao longo da cadeia produtiva e a questão da política social, acoplada à política econômica ampla e redistributiva. Movidas pelas atividades que se diferenciam e interagem, incluindo desde as matérias-primas, as máquinas e equipamentos, os produtos intermediários até o produto final, a distribuição e a comercialização, as cadeias também se distinguem, uma vez que se multiplicam as modalidades industriais, os arranjos produtivos intersetoriais e as formas de acumulação de capital.
} 
escolaridade mais elevada, habilidades específicas e conhecimento adequados à lean production - trouxe outros parâmetros para a ação sindical local.

Perscrutar a possibilidade paranaense de mais uma etapa de desenvolvimento industrial e da ação sindical desafiada a negociações descentralizadas e mais pontuais, significa apreender a dinâmica local do capitalismo que se internacionaliza, produzindo uma rede de dependências recíprocas em escala global, "com problemas e demandas multiplicadores e intensificadores em cada área particular, muito além do controle de qualquer "centro" singular, não importa quão poderoso e avançado seja esse, opina Mészáros (2002, p. 1075). A idéia de flexibilidade é a que mais se coaduna às novas demandas da produção material, da prestação de serviços que se informatiza e da atuação dos metalúrgicos da Grande Curitiba, por exemplo. Essa conjugação econômica e social forma os elos diferenciados da complexa cadeia automotiva. Para ordená-los, uma forma de governança é requisitada - a economic governance, capaz de conciliar interesses e de influenciar no sentido de resolver problemas de escassez numa produção puxada pela demanda.

As relações que se estabelecem geram novas institucionalidades (ARAÚJO, 2004) expressas nas dimensões local/global, regional/nacional, nos mercados, em hierarquias e nas redes, segundo Deyo e Doner (1997, apud. Abramo; Abreu, 2000), mas também na realidade sindical. Essa "sociedade em rede", na expressão de Castells (2000), exprime a nova divisão internacional do trabalho, onde fluxos econômicos e financeiros são os nós das redes internacionais com aportes regionais e locais, fazendo com que se cruzem atividades de diversas cadeias produtivas ${ }^{2}$. Subjazem a essa noção original, a referência à empresa como locus do produto, a percepção da relevância locacional na reespacialização da produção de bens e a sustentação de natureza sistêmica das relações dentro da empresa, entre empresas e, num corte transversal, entre regiões. Fica explícita a complexidade do fenômeno cadeias e redes e levanta a suspeita de sua influência sobre a ação sindical.

\footnotetext{
${ }^{2} \mathrm{O}$ interesse por cadeias produtivas foi movido pela crescente competitividade que se instaurou com o declínio da era fordista e despontou há pouco mais de uma década entre os estudiosos do trabalho em termos internacionais. Uma primeira coletânea na literatura da área foi organizada por Gereffi \& Korzeniewicz, em 1994, os quais trabalham a perspectiva global de cadeias de valor (Global Value Chains - GVC), apontando três características básicas de uma cadeia produtiva: uma estrutura de entrada e saída (input e output) do produto; os aspectos geográfico e locacional da produção, associados; a estrutura de governança que coordena a produção (Gereffi; Korzeniewicz, 1994, apud. KNORRINGA; PEGLER, 2003, p.2).
} 
As cadeias produtivas constituem ligações intersetoriais de atividades e processos concentrados na produção, que extrapolam o setor industrial. Ao mesmo tempo, reconhece-se nas redes, o dinamismo da nova fase do capitalismo mundial, envolvendo as empresas-mãe, os fornecedores e os consumidores ${ }^{3}$. Os efeitos das transformações no setor industrial, com a crescente demanda por atividades e a necessidade de maior integração entre a produção de bens e os serviços, fizeram multiplicar atividades e fluxos, afirma Dall'Acqua (2003), enquanto nexos mais ágeis entre diferentes segmentos da economia estabelecidos pelos avanços tecnológicos e as novas formas de gerenciar o trabalho.

A flexibilidade das empresas em rede passa a ser a lógica ordenadora do mercado 4 . Marcadas por mudanças nas relações inter-empresas, as cadeias produtivas expandem-se através de parcerias comerciais e de fornecimento, com implantação de atividades que respondem pelo controle e reposição dos estoques, movimentação de materiais e mesmo o desenvolvimento de processos e produtos. Tais alterações "têm conduzido a novas formas de arranjos inter-empresas, muitas vezes, em uma verdadeira "desfronteirização" das mesmas, ou seja, as relações tornam-se mais estreitas, com vínculos diretos que ultrapassam as relações entre os setores (MBC, 2003) e dão a dimensão do fluxo comercial exportador/importador a segmentos de uma cadeia produtiva, como o automotivo.

${ }^{3}$ O viés explicativo da densidade das redes tem obedecido à variável tecnológica, embora o componente estratégico operacional também se destaque como responsável pela competitividade instalada entre as empresas. Cobrindo graus de complexidade na agregação de valor ao que é produzido, Britto (2001, apud. TOYOSHIMA, 2001, p.3) apresenta quatro modelos de redes de produtos: a) Tradicionais: quando os produtos gerados apresentam um caráter não-complexo, sendo produzidos em escala reduzida, a partir de uma base de conhecimento relativamente simples, tais como as indústrias têxtil, de calçados, alimentar, de móveis e artefatos de metal; b) Modulares: quando o processo de produção envolve uma complexa hierarquia de componentes que necessitam ser integrados em nível de rede, como o das indústrias automobilística, de computadores e de equipamentos eletrônicos; c) Complexos: são arranjos orientados à obtenção de produtos sofisticados, intensivos em esforços de engenharia, cujos bens são produzidos em escalas reduzidas adaptando-se às exigências de consumidores individuais, como os sistemas de controle de tráfego aéreo, de automação bancária, de construção naval e aeronáutica; d) Redes de desenvolvimento tecnológico: são aqueles que se estruturam no intuito de viabilizar a geração e aplicação produtiva de novas tecnologias que se baseiam em conhecimentos complexos e requerem vultosos investimentos em P\&D, desempenhadas por empresas de "alta tecnologia" (high technology firms), tais como as indústrias de biotecnologia ótica, novos materiais e semicondutores. 
A flexibilidade incrementa a produtividade (maior produção com menos recursos) e permite encarar a concorrência com mudanças rápidas e constantes na tecnologia de produção. Tomada como imperativa, reconhece-se a flexibilidade interna e externa à empresa. A primeira, caracterizada pela polivalência, rotação e integração de tarefas, trabalho em equipe, é mais exercida por homens, enquanto a flexibilidade externa é característica dos empregos precarizados, de tempo parcial, horários flexíveis, tempo de trabalho anualizado, sendo mais exercida por mão-deobra feminina. Na flexibilidade externa, a empresa subcontrata e treina seu próprio pessoal para a polivalência, adaptando o trabalhador a novas situações, ajustando-o à sua tarefa, segundo Castel (1998). Pochmann (1998) chega a mencionar a flexibilidade quantitativa do mercado de trabalho, onde o rompimento dos contratos de trabalho denota a elevada rotatividade do emprego formal, no Brasil. Esses são aspectos característicos de cadeias produtivas e diferentes tratamentos dados à força de trabalho, conforme se posicionam as atividades em relação ao centro produtivo.

Embora as montadoras mantenham o core business e nele, o efetivo de trabalhadores é abrigado por contratos formais, no ambiente da empresa e/ou do condomínio industrial coexistem trabalhadores com contratos determinados e outros, com contratos temporários, além da realidade dos empregados das empresas terceiras, em atuação conjunta. Essa segmentação desde o interior das empresas até o mercado de trabalho amplo faz emergir o esgarçamento das relações de trabalho, conforme se afastam os elos da cadeia desse núcleo da atividade-fim da montagem na indústria automotiva. Diante deste quadro, crescem as dificuldades à ação coletiva, que se fragmenta e tende a diferenciações nas reivindicações.

Knorringa e Pleger (2003), com base em estudos realizados na área do trabalho e sobre cadeias produtivas globais, problematizam a relevância que

${ }^{4}$ A flexibilidade é a resposta-ritmo à introdução de novas tecnologias que Piore \& Sabel (1984) imputam à reconstituição das relações de trabalho e dos sistemas de produção em bases sociais, econômicas e geográficas inteiramente distintas das anteriores. Como princípio, a flexibilidade é uma habilidade do sistema produtivo de transitar entre diversos estados sem deteriorar custos, qualidade e tempos e Salerno (1992) percebe-a em 8 dimensões: a) social extra-empresarial, relativa à legislação social e sindical; b) estratégica, relativa à capacidade da empresa de mudar a estratégia de seus negócios; c) de volume de produção; d) de gama: capacidade de introduzir e retirar produtos, peças e componentes da linha; e) de mix, significa poder suportar alterações de produção dentro de uma dada gama de produtos e partes; f) de operações sazonais, relativa à capacidade de absorver alterações na demanda; g) para suportar o mal funcionamento do sistema de produção; h) para suportar erros de previsão. 
políticas industriais fazem do mix idéia/recurso/uso aplicado às cadeias produtivas, em países em desenvolvimento, especialmente na Índia e Brasil, na última década. Numa perspectiva crítico-política, indagam acerca dos meios para se obter "bom" emprego com "trabalho decente", conforme perspectivas da Organização Internacional do Trabalho $(\mathrm{OIT})^{5}$, ao serem avaliadas as possibilidades históricas e variadas de direitos dos trabalhadores e condições de trabalho em momentos produtivos de cadeias produtivas como a automotiva, onde as redes incluem, também, pequenas e médias empresas. Os questionamentos se movem no contraponto teórico entre as cadeias de valor global - Global Value Chains (GVC) e o contexto de pequenas e médias empresas - Small and Medium Enterprises (SMEs), as quais representam parte significativa da estrutura de emprego, exemplificado na produção de auto-peças. Valendo-se de pesquisa de Palpacuer (1997), os autores levantam a preocupação com o impacto sobre os trabalhadores a partir das mudanças que ocorrem em termos de flexibilidade, competitividade e adaptabilidade, como estratégias organizacionais baseadas em relações cooperativas que se estendem para além das empresas com os fornecedores, os consumidores, os concorrentes, já que também empresas pequenas e médias têm adotado relações de subcontratação.

Em se tratando de cadeias produtivas, está em jogo a análise das condições de integração das atividades, bem diferente do controle direto de um processo de produção de cima para baixo, verticalizado, como pretendia Ford, ao conceber a compra das firmas que fabricavam as peças para os automóveis (GOUNET, 2002, p. 19). A integração dos fluxos de produção implica integração no sentido sistêmico, própria da complexa e sofisticada direção da economia atual, que é a exigência de produzir e veicular um volume de informação cada vez maior, seja no interior da

\footnotetext{
${ }^{5}$ Diante da desigualdade entre os países, as regiões e os setores sócio-econômicos, a recomendação da busca universal por "trabalho decente" é de criação de oportunidades de trabalho com qualidade, segurança, proteção social e remuneração digna, principalmente nos países onde predomina a informalidade no mercado de trabalho. A origem da perspectiva do trabalho decente está nas principais convenções da OIT, aprovadas em 1998, em Genebra: liberdade de associação, direito à negociação coletiva, erradicação do trabalho infantil, combate ao trabalho forçado e eliminação de toda sorte de discriminação no trabalho. Ver Waisgrais, Trabajo decente en América Latina, Revista Latinoamericana de Estudios del Trabajo, a. 7, n. 14, 2001, pp. 91-108.
} 
organização, da empresa, do setor ou, mesmo, de um circuito produtivo amplo ${ }^{6}$. Essa integração sistêmica é proporcionada pela sintetização tempo/espaço, definida pela expressão "compressão tempo-espaço" de Harvey (1993). Há um movimento de estreitamento dos horizontes temporais da tomada de decisões privada e pública, que evoca a "difusão imediata das decisões num espaço cada vez mais amplo e variegado" (Idem, 1993, p. 140), e resulta do desenvolvimento da comunicação via satélite e da queda dos custos de transporte, fruto do avanço da tecnologia da informação.

A idéia de integração de atividades não é sustentada apenas pela função de sistemas eletrônicos de lógica binária, encontrada em indústrias de tecnologia avançada, mas também, pela coexistência necessária da não homogeneidade e sincronia das atividades em uma cadeia produtiva. Depara-se, aqui, com a chamada heterogeneidade na base econômica, uma tendência que se manifesta cada vez mais no Brasil, a partir dos anos 1990, como expressão da "modernização de empresas na ponta e do retraimento, fechamento e desnacionalização de outras empresas, ao longo da cadeia produtiva" (POCHMANN, 1998, p.146). Essas distinções em nível de mercado das empresas afetam, também, os trabalhadores

${ }^{6}$ A noção de cadeia produtiva, numa perspectiva sistêmica, tem sido analisada por Porter (1989, p. 52-53) que a relaciona com a agregação de valor e à logística, como sustentáculos que agrupam as atividades de uma empresa em duas categorias: a) infra-estrutura; administração dos recursos humanos e desenvolvimento de tecnologia; b) logística de operações (manufatura); logística de entrada, marketing e serviços de pós-venda, formando o conjunto das atividades primárias. Com a denominação de cadeia logística, refere-se aos elos entre o mercado e as atividades estratégicas, táticas e operacionais da empresa, envolvendo o planejamento, a implementação e o controle do fluxo de materiais, dos fornecedores até o cliente e, no sentido inverso, de fluxo de informações em busca de eficiência e eficácia através da coordenação e cooperação dentro da empresa e entre as empresas. A chave desse processo é a competição que, para Porter (1999, p.15), alimenta a produtividade crescente no uso dos recursos e pode ser estimulada; para tal, cunha a expressão "diamante da nação" ou "diamante da produtividade", referindo-se ao conjunto de variáveis estratégicas que criam um ambiente nacional dinâmico, impulsionado pelo Estado. Em tese, quatro variáveis se articulam para melhorar a vantagem competitiva de uma nação, ou seja: as condições dos fatores (insumos: recursos naturais, humanos e de capital); a infra-estutura física, administrativa, de informação, científica e tecnológica); as condições da demanda, traduzida pela base local de clientela, a estratégia, estrutura e rivalidade das empresas; e as indústrias correlatas de apoio, expressas no conjunto de fornecedores e distribuidores locais. Estudos neste campo têm transitado por unidades de análise mais complexas, demonstrando que o fenômeno das cadeias de valores não se restringe à perspectiva empresarial nem da empresa como um todo, mas enfatiza o setor e a estrutura setorial e, mais recentemente, deslocaram-se para a categoria atividade. Nesses termos, são desenvolvidas considerações acerca de aglomerados e localização geográfica (clusters) e, em sua teoria da vantagem competitiva, argumenta a favor da atividade como referencial básico para a estratégia internacional. Assim se expressa: "ao competir além-fronteiras, as empresas se tornam capazes de difundir suas atividades em inúmeras localidades, de modo a aproveitar as vantagens de cada uma e, ao mesmo tempo, assegurar, de várias maneiras, a coordenação entre atividades dispersas para auferir as vantagens da rede" (PORTER, 1999, p. 21). Observa-se a adoção de um comportamento competitivo, porque estimulado, em muitos segmentos produtivos, alterando as condições das atividades originais. 
organizados no local de trabalho e através dos sindicatos. Depara-se o país com o avolumar-se do problema do desemprego, da informalidade e a dificuldade de manutenção do emprego formal em cujas razões está a dinâmica da estrutura produtiva e seus efeitos sobre o mercado de trabalho. A internacionalização da base "criou uma integração produtiva estreita entre as empresas locais e suas congêneres no mercado internacional. (...) A incorporação dessas plantas a uma rede internacionalizada em contexto de ponderável exposição externa, provoca um processo recorrente de racionalização produtiva com impactos negativos permanentes sobre o nível de emprego local” (DEDECCA, 2001, p. 49).

Ao provocar segmentações no mercado de trabalho, expressam diferenças entre os setores econômicos e aguçam disparidades sociais, uma variante atualizada da polarização. Essas variações trazem nova concepção de desigualdade social, contraditória com o conceito de modernização, segundo Kern e Schumann (1988, apud. LEITE, 1995, p.337) e aparecem nas redes de subcontratação das cadeias produtivas, na combinação de formas modernas e tradicionais de uso do trabalho, nas diferenças das condições de trabalho em pequenas, médias e grandes empresas. As segmentações ocorrem, inclusive, no interior das empresas, seja pela divisão sexual do trabalho, seja pelo tratamento diferenciado quanto à qualificação, denominado "reatualização da discriminação" por Leite (Idem, p. 339). Heterogeneidade e discriminação são formas de controle de gestão da mão-de-obra7 .

Muitas implicações estão contidas numa discussão atualizada sobre cadeias produtivas e as tendências que se apresentam na economia, na sociedade e nos estudos. Não está em jogo apenas o upgrading (até compulsório) das empresas, a sua forma de governança mais ou menos participativa e descentralizada com a quebra de hierarquias, mas sobretudo, conceitos de poder embutidos nas relações de trabalho e no recurso à hierarquia utilizado nas análises. As relações industriais, a partir da tríade de negociações das condições de trabalho posta na empresa/sindicato/governo, têm se apresentado esgarçadas e mais vulneráveis em cadeias de valor, quando estão em jogo o crescimento do emprego pari passu ao

\footnotetext{
${ }^{7}$ Nas técnicas japonesas aplicadas no Brasil, sem a tradição empresarial e cultural originais, esse controle denota formas autoritárias de gestão e suposta autonomia do trabalho, traduzindo um sistema de vigilância que se apoia tanto na visibilidade natural do processo de produção e do desempenho do trabalhador na fábrica organizada sob os princípios do just-in-time e em sistemas de informação administrativa. (LEITE, 1995, p. 336-337).
} 
crescimento da produtividade, além da observância dos direitos do trabalhador no circuito da produção.

O processo de intensificação das relações sociais em escala mundial é de tal modo, que os acontecimentos locais são afetados, alterando-se sua extensão e profundidade com que a internacionalização do capitalismo acirrou a concorrência entre as empresas de diversos tamanhos e favoreceu a concentração do capital. Em paralelo e, paradoxalmente no mesmo processo, são produzidas realidades que existem à margem e, ao mesmo tempo, dependem dessa lógica. $\mathrm{O}$ crescimento do desemprego estrutural é mostra de que, concomitante ao estímulo à capacidade inovadora de diferentes segmentos produtivos, persistem os desafios para fazer frente à sobrevivência material de populações inteiras. Sem dúvida, a cadeia automotiva espelha esta crescente demanda por atividades relacionadas à organização, coordenação, supervisão, acesso a tecnologias e mercados associados ao setor industrial, mas também de distribuição, circulação e de regulação, extrapolando aquele setor. Um produto é fabricado em várias partes do mundo tomando por base a especialização, ou seja, "processos produtivos internacionalizados, nos quais etapas diferenciadas do processo realizam-se em diferentes países" (DALL'ACQUA, 2003, p. 46). Esse procedimento aparentemente de exclusividade econômica atinge a ação do sindicato, quando acontecem intercâmbios e comparações de realidades de políticas do trabalho entre os trabalhadores.

A cadeia automotiva, por exemplo, apresenta as duas características comuns ao fenômeno: extensão e complexidade de articulação, aplicando integralmente o paradigma da produção integrada e flexível. Essa, que emergiu nos anos 1970 e 1980, aposta no incremento das inovações tecnológicas e organizacionais de gestão da mão-de-obra, partindo da extração das matériasprimas necessárias à fabricação do veículo (borracha, ferro, cobre, chumbo, bauxita,...) e "passando por setores como a siderurgia, a indústria vidreira, a de pneus, a produção de autopeças (bielas, velas, freios...), depois pela montagem destes componentes em blocos diretamente utilizáveis no veículo (motor, carroceria, painel...), até chegar à montagem final e à venda, onde deságua a cadeia" (GOUNET, 2002, p 13). 
Um aspecto marcante das cadeias produtivas reproduzido na cadeia de produção de veículos é, sem dúvida o intercâmbio, as chamadas parcerias tecnológicas e produtivas ao longo da cadeia, em todos os níveis e de diferentes padrões. Entre elas estão as relações entre as montadoras, na ponta da cadeia e os fornecedores de itens fabris, resultando em um complexo uso de tecnologias mundiais, produção local, arranjos produtivos regionais (global sourcing ${ }^{8}$, follow sourcing ${ }^{9}$, condomínio, consórcio modular, etc.), desverticalização, desenvolvimento simultâneo de produto e processo, uso de sistemas e ferramentas de qualidade e logística integrada (supply chain management). Este sistema configura o que Zawislak (1999) denomina "cadeia totalmente integrada", ou seja, aquela que "sistematicamente reestruturada caracteriza-se por apresentar forte integração entre seus elos, o que se concretiza por meio de relações interfirmas pautadas por uma grande interdependência e concretas possibilidades de cooperação. (...) essas possibilidades ocorrem concomitantemente à existência de assimetrias de poder entre as empresas que participam da cadeia" (ZAWISLAK; MELO, 2002, p. 107). Essa é uma atuação em nível internacional e de regiões, exposta também na atuação sindical.

TABELA 1 - EVOLUÇÃO DO EMPREGO FORMAL NA CADEIA AUTOMOBILÍSTICA, POR CLASSE/GRUPO DE ATIVIDADE CNAE, NO PARANÁ - NOVEMBRO/2003

\begin{tabular}{|c|c|c|c|c|c|c|}
\hline \multirow{2}{*}{$\begin{array}{l}\text { SUBSETORES E GRUPO DE } \\
\text { ATIVIDADE CNAE }\end{array}$} & \multirow{2}{*}{\begin{tabular}{|c|} 
Estoque \\
em \\
$31 / 12 / 2002$
\end{tabular}} & \multicolumn{3}{|c|}{ Saldo de Emprego } & \multicolumn{2}{|c|}{ Variação (\%) } \\
\hline & & $\begin{array}{c}12 \\
\text { meses }\end{array}$ & $\begin{array}{l}\text { Ano } \\
2003\end{array}$ & Nov. 03 & $\begin{array}{c}12 \\
\text { meses }\end{array}$ & $\begin{array}{l}\text { No ano } \\
2003\end{array}$ \\
\hline $\begin{array}{l}\text { Fabricação de pneumáticos e câmaras } \\
\text { de ar }\end{array}$ & 460 & 212 & 208 & -7 & 46,49 & 45,22 \\
\hline $\begin{array}{l}\text { Fabricação de outras máquinas e } \\
\text { equipamentos de uso geral }\end{array}$ & 3.381 & 285 & 255 & 11 & 8,50 & 7,54 \\
\hline $\begin{array}{l}\text { Fabricação de baterias e acumuladores } \\
\text { para veículos }\end{array}$ & 934 & -15 & -24 & -19 & $-1,62$ & $-2,57$ \\
\hline $\begin{array}{l}\text { Fabricação de material elétrico para } \\
\text { veículos (exclusive baterias) }\end{array}$ & 875 & 296 & 211 & -12 & 37,47 & 24,11 \\
\hline $\begin{array}{l}\text { Fabricação de aparelhos e utensílios } \\
\text { para sinalização e alarme }\end{array}$ & 134 & -6 & -13 & -2 & $-4,72$ & $-9,70$ \\
\hline $\begin{array}{l}\text { Fabricação de automóveis, } \\
\text { caminhonetas e utilitários }\end{array}$ & 5.317 & -22 & -45 & -3 & $-0,42$ & $-0,85$ \\
\hline Fabricação de caminhões e ônibus & 80 & 197 & 212 & 12 & 207,37 & 265,00 \\
\hline $\begin{array}{l}\text { Fabricação de cabines, carrocerias e } \\
\text { reboque para caminhão }\end{array}$ & 1.141 & 54 & 67 & 5 & 4,68 & 5,87 \\
\hline
\end{tabular}


Fabricação de carrocerias para ônibus

Fabricação de cabines, carrocerias e reboque para outros veículos

Fabricação de peças e acessórios para o sistema motor

Fabricação de peças e acessórios para o sistema de marcha e transmissão

Fabricação de peças e acessórios para o sistema de freios

Fabricação de peças e acessórios para o sistema de direção e suspensão

Fabricação de peças e acessórios de metal para veículos automotores não classificados em outras classes

Recondicionamento e recuperação de motores para veículos automotores

Fabricação de produtos diversos

Comercio a varejo e por atacado de veículos automotores

Manutenção e reparação de veículos automotores

Comercio a varejo e por atacado de peças e acessórios para veículos automotores

Total

FONTE: MTE/CAGED

Elaboração: DIEESE/ER-PR

TABELA 2 - EVOLUÇÃO DO EMPREGO FORMAL NA CADEIA AUTOMOBILÍSTICA, POR CLASSE/GRUPO ATIVIDADE CNAE, NA REGIÃO METROPOLITANA DE CURITIBA - NOVEMBRO/2003

\begin{tabular}{|c|c|c|c|c|c|c|}
\hline \multirow{2}{*}{$\begin{array}{l}\text { SUBSETORES E GRUPO DE } \\
\text { ATIVIDADE CNAE }\end{array}$} & \multirow{2}{*}{$\begin{array}{c}\text { Estoque } \\
\text { em } \\
31 / 12 / 2002\end{array}$} & \multicolumn{3}{|c|}{ Saldo de Emprego } & \multicolumn{2}{|c|}{ Variação (\%) } \\
\hline & & $\begin{array}{c}12 \\
\text { meses }\end{array}$ & no ano & $\begin{array}{l}\text { Novem } \\
\text { bro-03 }\end{array}$ & $\begin{array}{c}12 \\
\text { meses }\end{array}$ & no ano \\
\hline $\begin{array}{l}\text { Fabricação de pneumáticos e câmaras } \\
\text { de ar }\end{array}$ & 450 & 232 & 227 & -8 & 52,13 & 50,44 \\
\hline $\begin{array}{l}\text { Fabricação de outras maquinas e } \\
\text { equipamentos de uso geral }\end{array}$ & 2.187 & 27 & 18 & -2 & 1,24 & 0,82 \\
\hline $\begin{array}{l}\text { Fabricação de baterias e acumuladores } \\
\text { para veículos }\end{array}$ & 0 & 0 & 0 & 0 & - & - \\
\hline $\begin{array}{l}\text { Fabricação de material elétrico para } \\
\text { veículos (exclusive baterias) }\end{array}$ & 418 & -32 & -34 & 1 & $-7,69$ & $-8,13$ \\
\hline $\begin{array}{l}\text { Fabricação de aparelhos e utensílios } \\
\text { para sinalização e alarme }\end{array}$ & 127 & -6 & -14 & -2 & $-5,04$ & $-11,02$ \\
\hline $\begin{array}{l}\text { Fabricação de automóveis, } \\
\text { caminhonetas e utilitários }\end{array}$ & 5.284 & -23 & -45 & -3 & $-0,44$ & $-0,85$ \\
\hline Fabricação de caminhões e ônibus & 80 & 197 & 212 & 12 & 207,37 & 265,00 \\
\hline $\begin{array}{l}\text { Fabricação de cabines, carrocerias e } \\
\text { reboque para caminhão }\end{array}$ & 479 & 6 & 17 & 10 & 1,22 & 3,55 \\
\hline Fabricação de carrocerias para ônibus & 365 & 165 & 170 & -2 & 44,59 & 46,58 \\
\hline
\end{tabular}


Fabricação de cabines, carrocerias e reboque para outros veículos

Fabricação de peças e acessórios para o sistema motor

Fabricação de peças e acessórios para o sistema de marcha e transmissão

Fabricação de peças e acessórios para o sistema de freios

Fabricação de peças e acessórios para o sistema de direção e suspensão

Fabricação de peças e acessórios de metal para veículos automotores não classificados em outras classes

Recondicionamento e recuperação de motores para veículos automotores

Fabricação de produtos diversos

Comercio a varejo e por atacado de veículos automotores

Manutenção e reparação de veículos automotores

Comercio a varejo e por atacado de peças e acessórios para veículos automotores

Total

FONTE: MTE/CAGED

Elaboração: DIEESE/ER-PR

TABELA 3 - EVOLUÇÃO DO EMPREGO FORMAL NA CADEIA AUTOMOBILÍSTICA, POR CLASSE/GRUPO DE ATIVIDADE CNAE, NO INTERIOR DO ESTADO DO PARANÁ - NOVEMBRO/2003

\begin{tabular}{|c|c|c|c|c|c|c|}
\hline \multirow{2}{*}{$\begin{array}{l}\text { SUBSETORES E GRUPO DE } \\
\text { ATIVIDADE CNAE }\end{array}$} & \multirow{2}{*}{$\begin{array}{c}\text { Estoque } \\
\text { em } \\
31 / 12 / 2002\end{array}$} & \multicolumn{3}{|c|}{ Saldo de Emprego } & \multicolumn{2}{|c|}{ Variação (\%) } \\
\hline & & $\begin{array}{c}12 \\
\text { meses }\end{array}$ & no ano & $\begin{array}{l}\text { Novem } \\
\text { bro-03 }\end{array}$ & $\begin{array}{c}12 \\
\text { meses }\end{array}$ & no ano \\
\hline $\begin{array}{l}\text { Fabricação de pneumáticos e câmaras } \\
\text { de ar }\end{array}$ & 10 & -20 & -19 & 1 & $-181,82$ & $-190,00$ \\
\hline $\begin{array}{l}\text { Fabricação de outras maquinas e } \\
\text { equipamentos de uso geral }\end{array}$ & 1.194 & 258 & 237 & 13 & 21,99 & 19,85 \\
\hline $\begin{array}{l}\text { Fabricação de baterias e acumuladores } \\
\text { para veículos }\end{array}$ & 934 & -15 & -24 & -19 & $-1,62$ & $-2,57$ \\
\hline $\begin{array}{l}\text { Fabricação de material elétrico para } \\
\text { veículos (exclusive baterias) }\end{array}$ & 457 & 328 & 245 & -13 & 87,70 & 53,61 \\
\hline $\begin{array}{l}\text { Fabricação de aparelhos e utensílios } \\
\text { para sinalização e alarme }\end{array}$ & 7 & 0 & 1 & 0 & 0,00 & 14,29 \\
\hline $\begin{array}{l}\text { Fabricação de automóveis, } \\
\text { caminhonetas e utilitários }\end{array}$ & 33 & 1 & 0 & 0 & 3,13 & 0,00 \\
\hline Fabricação de caminhões e ônibus & 0 & 0 & 0 & 0 & - & - \\
\hline $\begin{array}{l}\text { Fabricação de cabines, carrocerias e } \\
\text { reboque para caminhão }\end{array}$ & 662 & 48 & 50 & -5 & 7,23 & 7,55 \\
\hline Fabricação de carrocerias para ônibus & 0 & 141 & 141 & 25 & - & \\
\hline Fabricação de cabines, carrocerias e & 724 & 84 & 98 & 4 & 11,38 & 13,54 \\
\hline
\end{tabular}


reboque para outros veículos

Fabricação de peças e acessórios para o sistema motor

Fabricação de peças e acessórios para o sistema de marcha e transmissão

Fabricação de peças e acessórios para o sistema de freios

Fabricação de peças e acessórios para o sistema de direção e suspensão

Fabricação de peças e acessórios de metal para veículos automotores não classificados em outras classes

Recondicionamento e recuperação de motores para veículos automotores

Fabricação de produtos diversos

Comercio a varejo e por atacado de veículos automotores

Manutenção e reparação de veículos automotores

Comercio a varejo e por atacado de peças e acessórios para veículos automotores

Total

\begin{tabular}{rrrrrr}
147 & 65 & 63 & 4 & 44,83 & 42,86 \\
11 & 1 & 1 & 2 & 9,09 & 9,09 \\
191 & 18 & 19 & -1 & 9,38 & 9,95 \\
247 & 3 & 4 & 1 & 1,21 & 1,62 \\
& & & & & \\
870 & 70 & 67 & 1 & 8,07 & 7,70 \\
& & & & & \\
398 & -1 & 28 & 7 & $-0,23$ & 7,04 \\
1.419 & 204 & 237 & 14 & 14,05 & 16,70 \\
6.416 & 461 & 506 & 35 & 7,14 & 7,89 \\
7.528 & 694 & 747 & 63 & 9,15 & 9,92 \\
11.580 & 917 & 982 & 45 & 7,87 & 8,48 \\
& & & & & \\
32.828 & 3.257 & 3.383 & 177 & 9,88 & 10,31 \\
\hline
\end{tabular}

FONTE: MTE/CAGED

Elaboração: DIEESE/ER-PR

A seqüência de dados das Tabelas 1, 2 e 3 elaboradas pelo Dieese/2003 demonstra, não apenas a concentração de empregos na Região Metropolitana de Curitiba em relação ao restante do estado, como deixa claro estar nos subsetores de montagem (fabricação de veículos), distribuição e manutenção o contingente de trabalhadores. A variação percentual significativa no ano de 2003, comparado ao ano anterior, no item fabricação de caminhões e ônibus, corresponde à reestruturação e inovação na Volvo. A destacar, o crescimento significativo de fornecedores fabricantes de peças e acessórios para o sistema de freios, a produção de cabines e carrocerias, a fabricação de pneumáticos e câmaras de ar, bem como de peças para o sistema motor. Essa concentração industrial tem sua correspondência na localização e agilidade de negociações por parte do sindicato.

De modo concomitante, o aumento da produção de veículos para o mercado internacional e, principalmente, das exportações, leva à intensidade do ritmo de trabalho de montadoras e fornecedores conjugados, como atestam entrevistas com trabalhadores, sindicalistas e pessoal de hierarquia de decisões nas empresas em 
território paranaense. É neste sentido que este texto remete às relações industriais na sua amplitude de relações de trabalho, na tratativa que se estabelece entre o sindicato dos metalúrgicos, as empresas montadoras e fornecedoras e os seus trabalhadores, através de seus representantes internos, na forma de Comissões de Fábricas, de Delegados Sindicais, de trabalhadores cipeiros e de outras formas de representação constituídas por indicação, mas geralmente, mediante eleições.

O desenvolvimento do projeto integrado de pesquisa "Indústria automobilística no Paraná: relações de trabalho e novas territorialidades"/UFPRFundação Araucária (2003) tem demonstrado, mediante entrevistas, a ocorrência da assimetria de forças para os sindicatos de diferentes regiões e até nacionalidades. Nem sempre se dilatam as possibilidades da ação sindical mais efetiva, dadas as ameaças do capital internacional em retirar direitos e conquistas dos trabalhadores em determinada unidade e/ou país, que fazem recuar decisões coletivas em outras localidades. Um bolsão de ataques tem sido o número de empregados e a produtividade alcançada, sempre comparados. 
TABELA 4 - PRODUÇÃO E EMPREGO NA INDÚSTRIA AUTOMOBILÍSTICA - PARANÁ - BRASIL - 1997 A 2003

\begin{tabular}{|c|c|c|c|c|c|c|}
\hline \multirow[b]{2}{*}{ ANO } & \multirow[b]{2}{*}{ Empresa } & \multicolumn{2}{|c|}{ PARANÁ } & \multicolumn{2}{|c|}{ BRASIL } & \multirow{2}{*}{$\begin{array}{c}\text { Emprego/Prod } \\
\text { ução }\end{array}$} \\
\hline & & $\begin{array}{c}\text { Produção } \\
\text { Unid. }\end{array}$ & Emprego & $\begin{array}{c}\text { Produção } \\
\text { Unid. }\end{array}$ & Emprego & \\
\hline \multirow[t]{3}{*}{1997} & Volvo & 6.674 & 1.367 & & & \\
\hline & Renaut & Importados & 451 & 2.069 .703 & 115.349 & \\
\hline & Audi & & & & & \\
\hline \multirow[t]{3}{*}{1998} & Volvo & 6.380 & 1.314 & & & \\
\hline & Renaut & Importados & 906 & 1.586 .291 & 93.135 & \\
\hline & Audi & & & & & \\
\hline \multirow[t]{3}{*}{1999} & Volvo & 4.176 & 1.416 & & & \\
\hline & Renaut & 24.809 & 1.754 & 1.356 .714 & 94.472 & \\
\hline & Audi & & & & & \\
\hline \multirow[t]{3}{*}{2000} & Volvo & 6.272 & 1.792 & & & \\
\hline & Renaut & 58.083 & 2.456 & 1.691 .240 & 98.614 & \\
\hline & Audi & & & & & \\
\hline \multirow[t]{3}{*}{2001} & Volvo & 5.854 & & & & \\
\hline & Renaut & 71.108 & & 1.817 .116 & 94.055 & \\
\hline & Audi & & & & & \\
\hline \multirow[t]{3}{*}{2002} & Volvo & & & & & \\
\hline & Renaut & & & 1.791 .530 & 91.533 & \\
\hline & Audi & & & & & \\
\hline \multirow[t]{3}{*}{2003} & Volvo & & & & & \\
\hline & Renaut & & & 1.827 .038 & 90.807 & \\
\hline & Audi & & & & & \\
\hline 2004 & & & & & 101.300 & \\
\hline
\end{tabular}

FONTE: Anfavea, 1997-2004.

Com previsão de vendas internas para 2 milhões de unidades por ano, os fabricantes de veículos, no Brasil, argumentam a partir da concorrência com outros países, principalmente do Leste Europeu, China e Índia. A questão é complexa, pois 
associa de modo intenso economia e finanças, no âmbito público e privado internacional. A busca de garantia para a competitividade soa como uma ameaça à perda de condições para os investimentos, a produção, as vendas e a utilização dos veículos (Folha de São Paulo, 19 de novembro, 2004). Enquanto são firmados acordos bilaterais no comércio internacional, como com o México, visando ampliar para 210 mil unidades a serem vendidas, em 2005, a ameaça paira sobre os trabalhadores nacionais.

Hoje, as decisões sobre jornada de trabalho ou fechamento de setores e unidades em outras partes do mundo, ressoam muito objetivamente sobre as negociações locais, que já têm suas próprias dificuldades. Algumas mobilizações do Sindicato dos Metalúrgicos da Grande Curitiba, da luta pela PLR - Participação nos Lucros e Resultados à representação por local de trabalho, têm como pano de fundo esse movimento de mercado ainda centralizado nas grandes unidades matriciais, seja na Alemanha, seja na França ou em outras partes do mundo. O jogo estratégico das redes internacionais, nesses momentos de enxugamento dos custos, transforma-se em seqüência "dominó". Isso tudo porque, basicamente, as vendas que garantem os empregos estão atreladas a preço e qualidade.

Para o reconhecimento de cadeias produtivas fala-se, necessariamente, de concepções de espaço, territorialidade, redes, desenvolvimento local e economia regional, que interagem e expõem os vínculos que sustentam um circuito econômico. Noções e concepções reutilizadas com sentido determinado têm designado a natureza dos acontecimentos, cuja velocidade crescente coloca alternativas para a sociedade, como se uma nova razão avançasse sobre as coisas da natureza, da intervenção do homem sobre ela, sobre si mesmo e os fundamentos constitutivos do espírito. Faz-se referência ao pensamento da rede para explicar e entender a interação que acontece entre partes que não sobrevivem sozinhas ${ }^{10}$. O fenômeno não é novo. Nova é a exploração de sua dimensão de totalidade.

10 Derivado do ambiente dos neurobiólogos e dos investigadores da inteligência artificial, o conceito de rede remete, anatomicamente, à circulação do sangue no corpo humano, veias e nervos, canais de passagem e seus "entrelaçamentos". Por suas ramificações, a analogia com a árvore favorece a refundição de elementos tradicionais do conhecimento sem desestabilizá-los - a causalidade e a linearidade, o determinismo e a nãocontradição. Essa visão circularista do mundo, de um dentro orgânico que se automovimenta e provoca uma reprodução em si mesma, em termos teóricos e pragmáticos, permite tratar as redes como "formas de circulação sem começo nem fim, na medida em que as suas "junções" são múltiplas e os seus encaminhamentos complexos" (SFEZ, 1994, p. 259). Para a filosofia da ciência, a rede impõe-se como tecnologia do espírito (Idem, 1994, p. 10) e ao utilizar a analogia corpo/árvore passa da imagem do corpo com as múltiplas conexões no trabalho dos neurônios à imagem do mundo dos satélites, cabos, fibras óticas, mensagens telemáticas e gestão à distância, às ramificações possíveis em todos os sentidos nos circuitos de informação. 
O pensamento em termos de rede é aquele que pensa o sistema aberto, com toda a circulação possível, e não, o que está fora dele. Se tal dicotomia ocorre, em se tratando de países e suas economias por exemplo, é porque está se lidando com um paradoxo - propriedade de uma língua dizer o que diz ao mesmo tempo que o nega. "O paradoxo é sintoma de uma crise (...), sintoma de toda a sociedade quando se encontra mergulhada no duplo constrangimento de uma modernidade que não pode recusar e de tradições que a negam, tornando-se o paradoxo, símbolo de uma impotência a determinar-se", exprime-se Sfez (1994, p. 261). Há reversibilidade das partes e do todo: "a parte envolve a totalidade que ela exprime, enquanto a totalidade envolve a parte de que ela se exprime. Este envolvimento recíproco permite a passagem (e alimenta a ambigüidade) do sujeito à sociedade e da sociedade ao sujeito" (Idem, 1994, p. 261). Torna-se possível, por isso, remeter o sistema (totalidade) ao sujeito (trabalhador), considerado a expressão total de uma sociedade dividida.

Neste raciocínio, cindida, a sociedade não significa a morte da ação coletiva, ainda que o coletivo apresente-se fragmentado, mas a complementaridade entre as partes garante que a ação ocorra. Ela corresponde à inflexão nas regras do jogo no capitalismo avançado, para usar as palavras de Cardoso (1999), para quem essa ação será sempre uma ação de classe, "pensada como um processo conflitivo em que atores sociais se constituem mutuamente como coletivos em disputa pela determinação de um sentido ao devir, ou para imprimir a este devir um sentido (uma direção) segundo seu interesse" (Idem, p. 246).

A era dos paradoxos abre-se, então, como a necessidade de uma reestruturação espaco-temporal para toda e qualquer organização. Em outras palavras, não há desenvolvimento avançado de alguns países, segmentos sociais ou setores econômicos, sem que outros desenvolvimentos não se concretizem. Resta por alcançar a eqüidade entre eles. 


\section{REFERÊNCIAS}

ABRAMO, L.; ABREU, A. Produção flexível e novas institucionalidades na América Latina. In: ABREU, A. (org.). Produção flexível e novas institucionalidades na América Latina. Rio de Janeiro: Editora UFRJ, 2000, pp. 7-27.

BRITTO, J. Diversidade tecnológica e regimes de transação em redes de firmas. In: II Seminário Brasileiro da Nova Economia Institucional, 2001, Campinas. Anais... Campinas: UNICAMP, 2001, CD-ROM.

CARDOSO, A. M. A trama da modernidade; pragmatismo sindical e democratização no Brasil. Rio de Janeiro: Revan: IUPERJ-UCAM, 1999.

CASTEL, R. As metamorfoses da questão social; uma crônica do salário. Petrópolis: Vozes, 1998.

CASTELLS, M. A sociedade em rede. 3. ed. São Paulo: Paz e Terra, v. 1, 2000.

DALL'ACQUA, C. Competitividade e participação; cadeias produtivas e a definição dos espaços geoeconômico, global e local. São Paulo: Annablume, 2003.

DEDECCA, C. S. O trabalho no Brasil do anos 90. Revista Latinoamericana de Estudios del Trabajo, a. 7, n. 14, 2001, pp. 33-54.

Folha de São Paulo, São Paulo, 19 de novembro, 2004.

GEREFFI, G.; KORZENIEWICZ, M. (Eds.). Commodity chains and global capitalism. Westport: Praeger, 1994, apud. KNORRINGA, P.; LEE, P., 2003.

GOUNET, T. Fordismo e toyotismo na civilização do automóvel. São Paulo: Boitempo, 2002.

HARVEY, D. A condição pós-moderna. Uma pesquisa sobre as origens da mudança cultural. São Paulo: Loyola, 1993.

KNORRINGA, P.; LEE, P. Perceptions of labour rights and conditions: SMEs and Global Value Chains. EADI Workshop "Working in Small Enterprises - Job Quality and Labour Conditions in a Globalising World, Amsterdã, 2003, (mimeo).

LEITE, M. Inovação tecnológica e relações de trabalho: a experiência brasileira à luz do quadro internacional. In: CASTRO, N. (Org.). A máquina e o equilibrista: inovações na indústria automobilística brasileira. Rio de Janeiro: Paz e Terra, 1995, p. 335-360.

MBC - Movimento Brasil Competitivo. Núcleo de Estudos em Estratégia e Desenvolvimento (local) Norte Fluminense. http://www.mbc.org.br/cadeias/cadeias.asp. Acesso em 19/11/2003.

MÉSZÁROS, I. Para além do capital; rumo a uma teoria da transição. São Paulo: Boitempo; Campinas: Editora da UNICAMP, 2002.

NABUCO, M. R.; NEVES, M.; CARVALHO NETO, A. (Orgs.). Indústria automotiva: a nova geografia do setor produtivo. Rio de Janeiro: DR\&A, 2002. 
PALPACUER, F. Competitive strategies, competencies management and interfirme networks: a discussion of current changes and implications for employment. International Workshop - Global Production Systems and Labour Markets, IILS, 1997, apud. KNORRINGA, P.; LEE, P., 2003.

PIORE, M. J.; SABEL, C. The second industrial divide: possibilities for prosperity. New York: Basic Boooks, 1984.

POCHMANN, M. Os desafios do sindicalismo brasileiro neste final de século. Revista de Sociologia e Política, n. 10/11, p.139-152, 1998.

PORTER, M. Competição on competition; estratégias competitivas essenciais. 9.ed. Rio de Janeiro: Campus, 1999.

PORTER, M. A vantagem competitiva das nações. Rio de Janeiro: Campus, 1989.

SALERNO, M. S. flexibilidade e organização produtiva: elementos para transformar o termo flexibilidade numa categoria analítica: elementos para análise da produção na indústria. XVI Encontro Anual da ANPOCS, Caxambu, 1992.

SFEZ, L. Crítica da comunicação. Lisboa: Instituto Piaget, 1994.

TOYOSHIMA, S.; CARNEIRO, P.; BARRETO, R. Inovações organizacionais e tecnológicas da indústria de autopeças mineira e suas relações com a FIAT Automóveis S.A. Universidade Federal de Viçosa, 2001, 11 p. (mimeo).

WASGRAIS, S. Trabajo decente en América Latina. Revista Latinoamericana de Estudios del Trabjo, a. 7, n. 14, 2001, pp. 91-108.

ZAWISLAK, P. A. (Coord.) Plataforma tecnológica da cadeia automotiva do Rio Grande do Sul. Porto Alegre: Nitec/PPGA/UFRGS-FIERGS-PADCT, 1999.

ZAWISLAK. P. A.; MELO, A. A indústria automotiva no Rio Grande do Sul: impactos recentes e alternativas de desenvolvimento. In: NABUCO, M. R.; NEVES, M.; CARVALHO NETO, A. (Orgs.). Indústria automotiva; a nova geografia do setor automotivo. Rio de Janeiro: DP\&A Editora, 2002, pp. 105-138. 